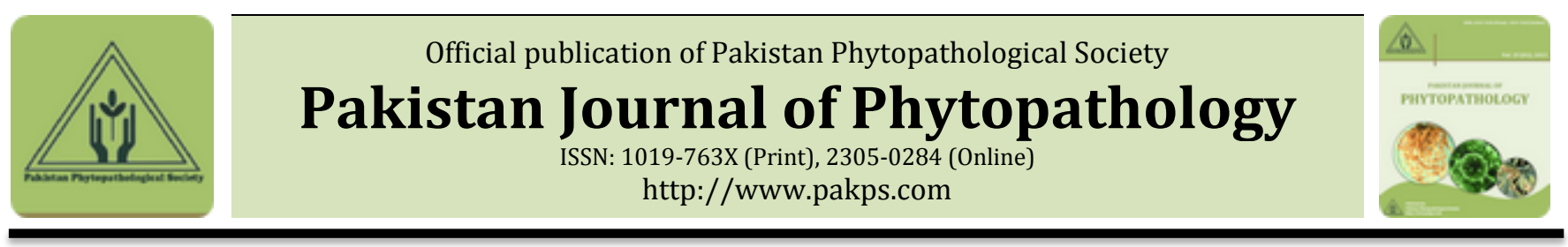

\title{
POTATO VIRUS Y: AN EVOLVING PATHOGEN OF POTATO WORLDWIDE
}

\author{
Khalid Naveed, Amjad Abbas, Luqman Amrao
}

Department of Plant Pathology, University of Agriculture, Faisalabad, Pakistan.

\section{A B S T R A C T}

Potato virus $Y(\mathrm{PVY})$ is one of the important diseases of potato throughout the world wherever potatoes are grown. Yield losses in potato due to PVY are up to $70 \%$ if infection occurs at initial growth stages of plants. More than eight PVY strains have been reported worldwide which differ from each other based on symptoms they produce in the infected host plants and at their genetic makeup. In recent past years, new necrotic strains of PVY have emerged which are more damaging as they produce necrotic rings and arms on the tubers of infected plants. With increasing aphid population during last decade, incidence of PVY epidemics has increased worldwide. Managing PVY is difficult as some strains do not produce symptoms on infected potato plants and disease diagnosis becomes difficult. In Pakistan, work on strain differentiation of PVY and their aphid vectors are lacking and there is need of molecular research to identify PVY strains which are present in Pakistan.

Keywords: Potato virus Y, Necrotic Arcs, Resistance, Strains

Potato virus $Y$ (PVY) belongs to the genus Potyvirus and family Potyviridae. Its genome is single-stranded RNA (ssRNA) which is $9.7 \mathrm{~kb}$ in size (Ward and Shukla, 1991). More than 10 different species of aphids transmit PVY in non-persistent manner. PVY is also called common mosaic of potato or potato severe mosaic. Green peach aphid (Myzus persicae) is most efficient vector in transmitting PVY in potato (Halbert et al., 2003). In addition to potato, it infects tobacco, tomato, pepper, eggplant and several other plant species in the families of Chenopodiaceae and Malvaceae (Kerlan, 2006). Several new PVY strains have been discovered worldwide which produce different symptoms in infected potato plants and are different from each other at their genetic levels (Boonham et al., 2002a). Three main strains of PVY are reported: PVY-C (common), PVY-O (ordinary strain) and PVY-N (tobacco veinal necrotic strain). Several recombinant strains have emerged which include PVY-NTN, PVYNTN/N, PVY and N: Wi which have emerged as a result of recombination between ordinary and necrotic strains (Lorenzen et al., 2006).

* Corresponding Author:

Email: kahlidnaveed1673@gmail.com

(c) 2017 Pak. J. Phytopathol. All rights reserved.
PVY was not considered a serious problem until the 1980 's as the management was easy. However, after 1980's several necrotic strains have emerged which do not produce visible symptoms on potato plants. During the last two decades, new recombinant necrotic strains have made difficult the management of PVY. The symptoms of recombinant necrotic strains are not visible on infected plants which results in disease escapes during disease inspection surveys. PVY infection in potato crop may result in $10-100 \%$ yield reduction depending upon the stage of plant and virus strain. PVY recombinants have emerged due to recombination between ordinary (PVY-O) and necrotic strain (PVY-N) which are more devastating than the original strains. In potato, PVY is a serious yield constraint that can cause losses as much as $50-80 \%$ in heavily infected commercial potato fields. PVY persists in seed potatoes which are used for growing the next potato crop (Hane and Hamm, 1999). A novel recombinant strain of PVY-O was reported that reacts with PVY-N specific monoclonal antibody IF-5 and named as PVYO-05. The genome of PVY carries Hc-Pro (helper component protease) protein that is involved in vector transmission of PVY and mediates vector specifity (Karasev et al., 2011). 
In addition to transmission through aphids, PVY is spread to healthy plants through mechanical means which can be a wound or insect injury resulting in the spread. Research has shown that plants growing next to infected plants also become infected at the end of the season possible due to mechanical spread or through the rubbing of leaves. From Pakistan, knowledge about different strains of PVY and its aphid vector is lacking. The necrotic strains of PVY: tobacco veinal-necrotic strain (PVY-N) and tuber-necrotic strain (PVY-NTN) have become a serious problem in seed production areas as the plants do not produce visible foliage symptoms whereas the tubers of infected plants exhibit severe necrosis, which reduces the market price of the produce (Karasev et al., 2011; Singh et al., 2008; Boonham et al., 2002b; Beczner et al., 1984).

Ordinary strain of PVY: The ordinary strain (PVY-O) was prevalent in potato fields in North America and other countries of Europe until 1980. PVY-O produces mosaic, mottling and stunting symptoms on infected potato plants. Symptoms of PVY differ in different

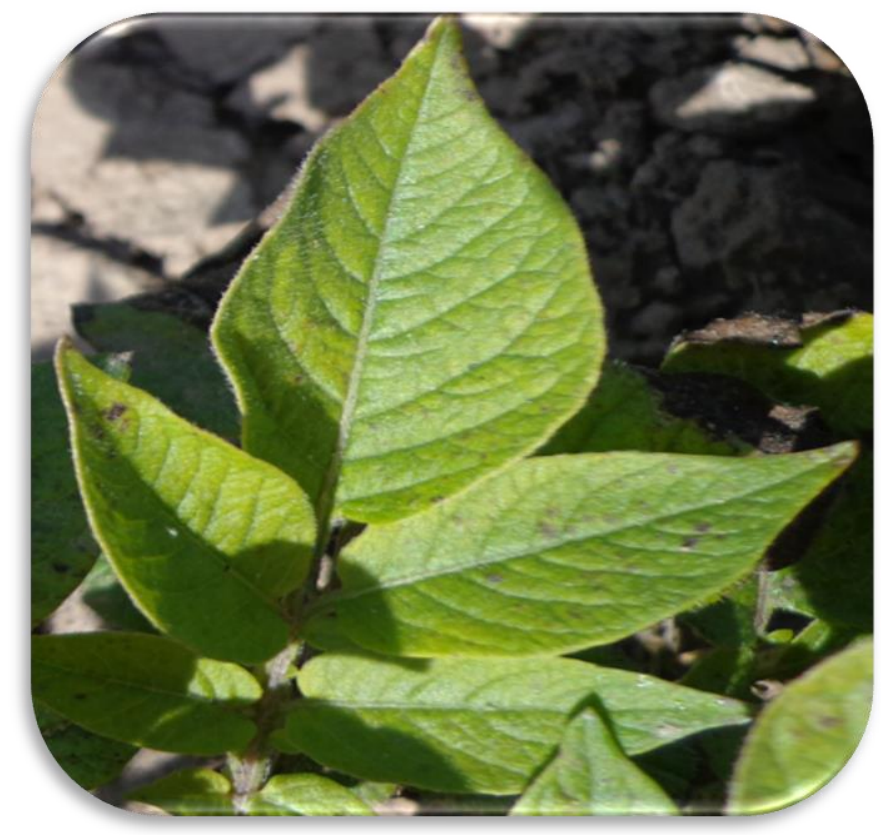

potato varieties which show a range of symptoms whereas some varieties do not show visible symptoms in response to PVY infection. PVY-O infection was easy to diagnose from the symptoms during field inspection surveys. Diagnosis of diseased plants helps in management of the pathogen in potato crops (Nolte et al., 2010).

Necrotic strains: PVY-N was reported from Europe and United States after the 1980's. "N" stands for necrosis produced in tobacco plants in response to infection whereas necrosis is not shown on potato plants. Most potato varieties do not show any symptoms in response to PVY-N infection PVY-N produces necrosis on tobacco leaves but symptoms on potato plants are very mild (Karasev et al., 2011; Singh et al., 2008). In case of PVY-NTN infection, tubers of some varieties show necrotic rings which renders them unmarketable. Tubers infected with PVY-NTN are unfit for human consumption that results in huge economic impact (Karasev et al., 2008; Beczner et al., 1984).

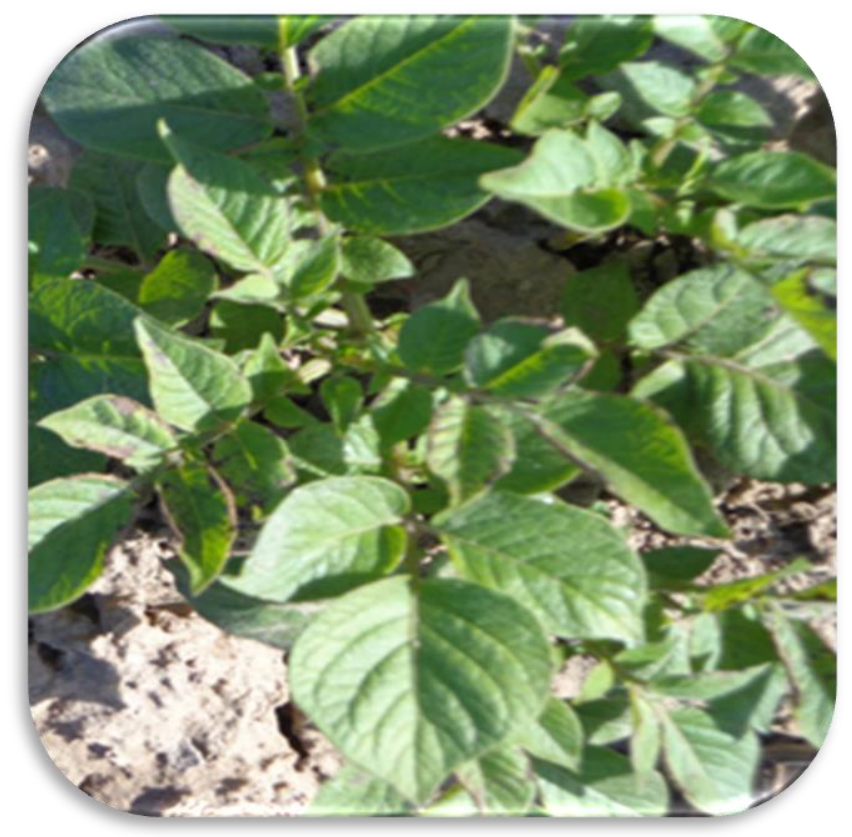

Figure 1. Potato plant showing mosaic and stunting symptoms due to infection with Potato virus $Y$.

(a) Desiree plant showing mosaic symptoms due to PVY infection (b) mild mosaic exhibited by potato in response to PVY infection Status of PVY in Pakistan: Different studies have been conducted which report prevalence of different potato viruses in Pakistan including Potato virus $X$, Potato leaf roll virus, Potato virus $Y, M$ and Potato virus A (Abbas et al., 2012). From Pakistan, PVY-O and PVY-N strains have been reported and data about other strains is missing. There is need to characterize PVY strains in potato fields in Pakistan in order to develop better management strategies. Mixed virus infections are common in potato and synergism as well as antagonism has been observed in mixed virus infections in potato (Hameed et al., 2014). In a study from Pakistan, determined the incidence of major potato viruses was checked in spring, autumn and summer crops from different ecological zones of Khyber 
Pakhtunkhwa. From 76 fields, 1338 samples were collected and tested by dot-blot immunoassays using antisera to six potato viruses: PLRV, PVY, PVX, PVS, PVM and PVA. PVY and PLRV were detected at high incidence from all districts and three other viruses PVS, PVX and PVM were also detected from summer crop and PVX was detected from spring crop (Ali et al., 2012). Abbas et al., (2012) reported the infection by six potato viruses: Potato virus $Y$ (PVY), Potato leafroll virus (PLRV), Potato virus $S$ (PVS), Potato virus $X$ (PVX), Potato virus $M$ (PVM) and Potato virus $A$ (PVA) in potato growing areas in Punjab. PVY incidence was high in all potato fields followed by PVX, PVA, PVS, PVM and PLRV. In another study, Potato virus $Y$ (PVY), Potato virus $S$ (PVS) and Potato virus $X$ (PVX) were detected in major potato growing areas: Faisalabad, Pakpattan and Sahiwal using ELISA and PCR. The data showed the presence of all three viruses in potato plants and PVX was detected from all districts followed by PVY and PVS. There was also varietal difference in the distribution of three viruses: PVX was found in Desiree and Diamont samples whereas PVY was recovered maximum from Cardinal and Desiree (Burhan et al., 2007). Another research group surveyed potato fields in Pakistan by focusing on two major potato cultivars being grown in Pakistan: samples from Desiree and cardinal were collected and checked for the presence of different potato viruses: PVS, PVM, PVA, PVY, PVX and PLRV. The data showed multiple virus infection in single plants. PVY, PVS and PVX were detected in many potato fields and coinfections were found in case of PVS and PVY (15.5\% incidence). Doubly-infected plants showed higher virus titres in comparison to singly infected plants (Hameed et al., 2014).

Recently, Abbas et al., (2014) reported PVY necrotic trains from Pakistan. Potato samples were collected from potato fields of Rawalpindi, Islamabad, Sahiwal and Faisalabad during 2010-11 and 2011-12. Samples were tested through double-antibody sandwich enzyme-

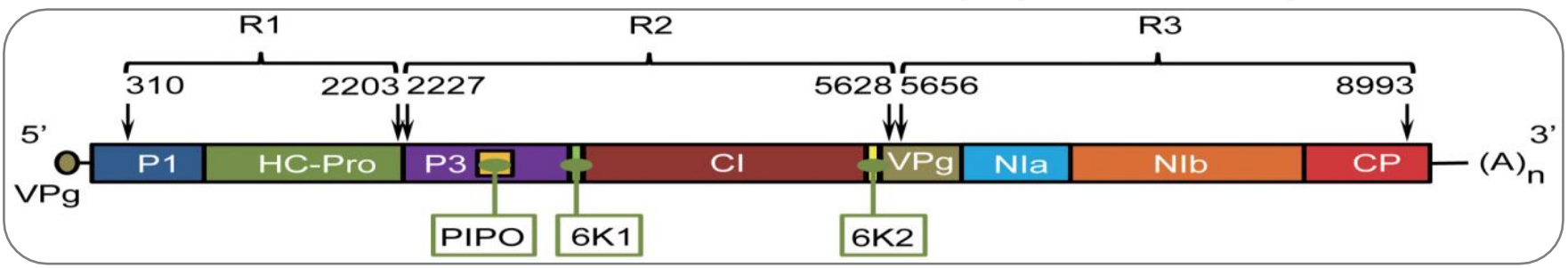

Figure 2. Genome organization of Potato virus Y. The genome is $9700 \mathrm{bp}$ in size with ploy-A tail at the 3 end and VPg

protein at the 5 end of the genome. Source Cuevas et al., (2012). PLOS ONE. linked immunosorbent assay (DAS-ELISA) which ELISA results, PVY incidence increased during the year 2011-12 than the previous year by $9 \%, 10 \%, 17 \%$ and $22 \%$ in potato fields $\mathrm{n}$ Sahiwal, Islamabad, Faisalabad and Rawalpindi respectively. The phylogenetic analysis of coat protein of PVY showed that the isolates belonged to the group of PVYNTN /PVYNTN:N with the minimum genetic diversity whereas PVY-C group showed maximum genetic diversity. Potatoes harvested from previous season are mostly used for growing the next season crop in Pakistan. Symptoms of PVY are not visible on seed tubers and farmers sow the infected seeds which results in PVY infection in the new crop.

Genome organization of PVY: PVY particles are filamentous and non-enveloped which are $680-900 \mathrm{~mm}$ in length and 11-15 $\mathrm{nm}$ in diameter. Its genome encodes for 9 different proteins which perform different functions during virus life cycle. Its genome is singlestranded positive sense RNA (ssRNA) which is $9.7 \mathrm{~kb}$ in size (Ward and Shukla, 1991). The 5' end of the genome is covalently linked to VP'g protein and $3^{\prime}$ end has a polyadenylated tail (Shukla et al., 1994). The genome acts as messenger RNA and is expressed as a large polyprotein $(3.5 \mathrm{KDa})$ and $\mathrm{VP}^{\prime} g$ enhances translation process. The polyprotein is cleaved into 10 different proteins which have different roles. Its genome encodes for three proteases which are involved in cleavage of large polyprotein resulting in the formation of several multifunctional proteins which perform various functions during virus life cycle. These include PI, helper component proteinase (Hc-Pro), P3, nuclear inclusion protein a (NIa), cytoplasmic inclusion (CI) protein, nuclear protein $\mathrm{b}(\mathrm{NIb}), 6 \mathrm{~K} 1,6 \mathrm{~K} 2$ and coat protein $(\mathrm{CP})$ (Fauquet et al., 2005). Hc-Pro performs different roles and is involved in aphid transmission and determines vector specificity (Flasinki and Cassidy, 1998). P1, HcPro and NIb are proteases which are involved in cleavage of polyprotien into smaller proteins. showed the presence of PVY in samples. According to

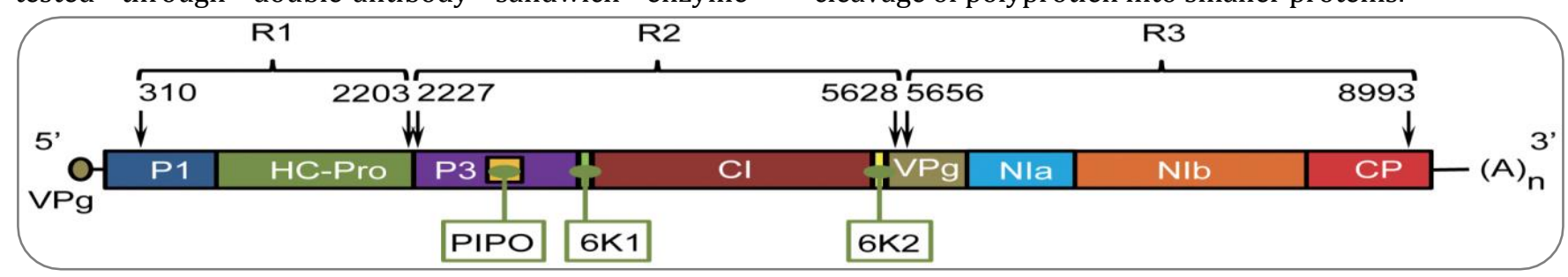


Management strategies for PVY: For PVY transmission, the aphids don't need to colonize the plants in order to acquire and transmit the virus to healthy plants. Insecticide sprays are ineffective as the contact time between the aphid and the insecticide is very short that renders insecticides ineffective. Insecticides only show effectiveness after they enter into insect body in case of persistently-transmitted viruses. In case of viruses transmitted in persistent manner, aphids ingest the plant sap for longer periods of time and the virus circulates inside insect body before it can be transmitted to new plants. Insecticides have been found useful in case of Potato leaf roll virus (PLRV) which is persistentlytransmitted virus and the aphids need to colonize the plants for longer hours in order to transmit the virus. Different insecticides are recommended to control PVY spread in fields which include imidacloprid, thiamethoxam, clothianadin, and acetamiprid. These insecticides can be applied in furrows, as foliar sprays and as seed treatments (Schramn et al., 2012). Minerals oils have been found useful in the control of PVY spread in potato fields. Different studies suggest that the use of mineral oils is effective in reducing PVY spread. A study evaluated the efficacy of Superior 70 and Vazyl-Y against PVY. The result showed that in oil treated plots PVY was much less in comparison to control plots (Fageria et al., 2014). Crop border is also effective in managing PVY in potato crops. Crop border acts as a virus sink in controlling PVY and if combined with mineral oils provides effective control of PVY spread. Fields trials conducted over the period of 3 years showed that combining foliar mineral oil sprays with crop borders provides twice effective control of PVY in comparison to crop border alone (Boiteau et al., 2008). Infected potato seed tubers result in PVY spread in new crop. Farmers in Pakistan are using the seed from previous crop for getting the next crop, so there is need to emphasize on the use of clean and virus free ELISA-tested seed. Seed certification departments should sell virus free potato seed tubers to potato growers on cheap rates. Famers should be advised about the losses due to PVY as it can result in $70-80 \%$ yield losses in severe infections. RNAi technology can be used to generate resistance in potato cultivars against newly emerging necrotic strains in order to control the disease. Genetically-engineered resistance against field PVY isolates can provide long term control of PVY as new strains are emerging which result in resistance break down governed by $\mathrm{R}$ genes.

\section{REFERENCES}

Abbas, M. F., S. Hameed and C. A. Rauf. 2014. Presence of new strain of Potato virus $Y$ in Pakistan. Int. J. Agric. Biol. 16: 941-945.

Abbas, M.F., S. Hameed, A. Rauf, Q. Nosheen, A. Ghani, A. Qadir and S. Zakia. 2012. Incidence of six viruses in potato growing areas of Pakistan. Pak. J. Phytopathol. 24: 44-47.

Ali, A., S. Hassan, A. Asad. 2002. Incidence of six potato viruses in spring, summer and autumn potato crops of the North West Frontier Province of Pakistan. Aus. Plant Pathol. 31:143-146.

Beczner, L., J. Horvath, I. Romhanyi, and H. Foorster. 1984. Studies on the etiology of tuber necrotic ringspot disease in potato. Potato Res. 27: 339-3.

Boiteau, G., M. Singh and J. Lavoie. 2008. Crop border and mineral oil sprays used in combination as physical control methods of the aphid transmitted potato virus Y in potato. Pest Manag. Sci. 65 (3): 255-259.

Boonham, N., K. Walsh, M. Hims, S. Preston, J. North, and I. Barker. 2002b. Biological and sequence comparisons of Potato virus $Y$ isolates associated with potato tuber necrotic ringspot disease. Plant Pathol. 51: 117-126.

Burhan, M., M. A Khan, M. Irfanullah, M.R. Jameel and M. Ishfaq. 2007. Incidence of Potato virus X, Potato virus $\mathrm{Y}$, Potato virus $\mathrm{S}$ on potato cultivars in potato growing areas. J. Agric Soc. Sci. 3(1): 37-38.

Cuevas, J. M., A. Delaunay, J. C. Visser, D. U. Bellstedt, E. Jacquot, and S. F. Elena. 2012. Phylogeography and molecular evolution of Potato virus Y. PLOS ONE. PLoS ONE 7(5):37853. doi:10.1371/ journal.pone.0037853

Fageria, M. S., S. Boquel, G. Leclair, and Y. Pelletier. 2014. The use of mineral oils in potato protection, dynamics in the plant and effect on Potato virus $Y$ spread. AJPR. 91 (5): 476-484.

Fauquet, C. M., M. A. Mayo J. Maniloff, U. Dessel-berger, L. A. Ball. 2005. Virus taxonomy. Eighth Report of the International Committee on Taxonomy of Viruses. Elsevier Academic Press, San Diego, CA, USA, 1259 pp.

Flasinki, S. and B.G. Cassidy. 1998. Potyvirus aphid transmission requires helper component and homologous coat protein for maximal efficiency. Arch. Virol. 143(11): 2159-72.

Halbert, S. E., D. L. Corsini and M. A. Wiebe. 2003. Potato virus $Y$ transmission efficiency for some common aphids in Idaho. Amer. J. Pot. Res. 80: 87-91. 
Hameed, A., Z. Iqbal, S. Asad and S. Manoor. 2014. Detection of multiple potato viruses in field suggests synergistic interaction among potato viruses in Pakistan. Plant Pathol J. 30 (4): 407-415.

Hane, D. C. and P.B Hamm. 1999. Effects of seed-borne Potato virus $Y$ infection in two potato cultivars expressing mild disease symptoms. Plant Dis. 83: 43-45.

Karasev, A. V., T. Meacham, X. Hu, J. L. Whitworth, S. M. Gray, N. Olsen and P. Nolte. 2008. Identification of Potato virus $Y$ Strains Associated with Tuber Damage during a Recent Virus Outbreak in Potato in Idaho. Plant Dis. 92: 1371.

Karasev, A. V., X. Hu, C. J Brown, C. Kerlan, O. V. Nikolaeva, J. M. Crosslin and S.M. Gray. 2011. Genetic diversity of the ordinary strain of Potato virus Y (PVY) and origin of the recombinant PVY strains. Phytopathol. 101(7): 778-785.

Kerlan C. 2006. Potato Virus Y. CMI/AAB Descriptions of Plant Viruses 414.
Lorenzen, J. H., T. Meacham, P. H. Berger, P. J. Shiel, J. M. Crosslin, P. B. Hamm and H. Kopp. 2006. Whole genome characterization of Potato virus $Y$ isolates collected in western USA and their comparison to isolates from Europe and Canada. Arch. Virol. 151: 1055-1074.

Nolte, P., J. M. Alvarez and J. L. Whitworth. 2010. Potato virus $Y$ management for the seed potato producer. (https://www.cals.uidaho.edu/edcomm/pdf/CIS/C IS1165.pdf)

Singh, R. P., J. P. Valkonen, S. M. Gray, N. Boonham, R.A. Jones, C. Kerlan, and J. Schubert. 2008. Discussion paper: The naming of Potato virus $Y$ strains infecting potato. Arch. Virol. 153: 1-13.

Shukla, D. D., C. W. Ward and A. A. Brunt. 1994. The Potyviridae. CABI University Press. Cambridge UK.

Ward, C.W. and D.D. Shukla 1991. Taxonomy of Potyviruses. Current problems and possible solutions. Intervirology. 32: 269-296. 